Ambiente \& Água - An Interdisciplinary Journal of Applied Science
ISSN 1980-993X - doi:10.4136/1980-993X
www.ambi-agua.net
E-mail: ambi-agua@agro.unitau.br

\title{
Vulnerabilidade à contaminação das águas subterrâneas do município de Nova Palma, Rio Grande do Sul, Brasil
}

\author{
doi: 10.4136/ambi-agua.1390
}

Received: 05 May 2014; Accepted: 02 Oct. 2014

\author{
Carlos Alberto Löbler ; José Luiz Silvério da Silva \\ Universidade Federal de Santa Maria (UFSM), Santa Maria, RS, Brasil \\ *Autor correspondente: e-mail: carloslobler@gmail.com, \\ silverioufsm@gmail.com
}

\section{RESUMO}

A água subterrânea é um componente muito importante do ciclo hidrológico e exerce papel relevante, muitas vezes imperceptível aos olhos humanos. Esta pesquisa apresenta um estudo de caso da aplicação do sistema GOD na avaliação da vulnerabilidade do aquífero à contaminação. Foram pesquisados 36 poços tubulares de captação de água subterrânea do município de Nova Palma, cadastrados e situados na borda da Bacia Sedimentar do Paraná na região central do estado do Rio Grande do Sul, Brasil. Ocorrem dois sistemas de aquíferos na área em estudo: um constituído pelos derrames vulcânicos de rochas básicas e ácidas formadores do Sistema Aquífero Serra Geral (SASG) e outro, constituído de formações sedimentares arenosas, denominado de Sistema Aquífero Guarani (SAG), tanto em sua zona de afloramentos quanto na de confinamento. A água subterrânea no município é utilizada no abastecimento humano e outros usos. A aplicação do Sistema GOD indicou 8\% das captações em área da classe de vulnerabilidade insignificante; $15 \%$ baixa; $31 \%$ média; $31 \%$ alta e ainda, $15 \%$ da classe extrema. Os pontos potenciais de contaminação das águas subterrâneas identificados foram sete cemitérios e dois postos de combustíveis, os quais foram espacializados em cartogramas. Estes resultados poderão ser aplicados no planejamento do uso e ocupação dos solos do município, além de contribuir para a preservação dos recursos hídricos subterrâneos.

Palavras-chave: Geotecnologias, Sistema Aquífero Guarani, Sistema GOD.

\section{Contamination vulnerability of groundwater in the municipality of Nova Palma, Rio Grande do Sul, Brazil}

\begin{abstract}
While often imperceptible to the human eye, groundwater has a relevant role as a very important component of the hydrological cycle. This research presents a case study of the GOD system assessing the vulnerability of the aquifer to contamination. The study surveyed thirty-six groundwater extraction wells in the municipality of Palma Nova, registered and located on the edge of the Paraná Sedimentary Basin in the central region of Rio Grande do Sul, Brazil. Two aquifer systems occur in this area in both outcropping and confined zones; one is composed of volcanic flows known as the Serra Geral Aquifer System (SGAS) and the other of sedimentary sandstone rocks, known as the Guarani Aquifer System (SAG). The
\end{abstract}


GOD method indicates that $8 \%$ of the wells are in the insignificant class of vulnerability, $15 \%$ in the low class, $31 \%$ in the moderate class, $31 \%$ in the high class and $15 \%$ in the extreme vulnerability class. Seven cemeteries and two gas stations were identified as pollution source points. These results could be used for land use planning by the municipality's administration as well as for the preservation of groundwater quality.

Keywords: GIS technology, GOD method, Guarani aquifer.

\section{INTRODUÇÃO}

A interação homem natureza ocasiona modificações no meio. O homem detentor de técnicas, que se aprimoraram com o passar dos anos, busca alternativas para planejar o melhor uso e ocupação do espaço. Atividades como a indústria e a agricultura podem, no entanto, ocasionar danos ao meio ambiente e aos recursos hídricos, tanto superficiais como subterrâneos.

$\mathrm{Na}$ agricultura os diversos tipos de cultivos utilizam águas subterrâneas para irrigação e ainda podem gerar elevadas concentrações de alguns elementos químicos, pelo uso de fertilizantes e defensivos agrícolas.

O declínio da qualidade da água tornou-se uma questão global, relacionado ao crescimento da população e, especialmente, à expansão das atividades industriais e agrícolas. As mudanças climáticas também causando importantes alterações no ciclo hidrológico (UM-Water, 2011). A Comunidade Europeia estabeleceu normas importantes, como a Diretiva Quadro da Água (DQA) e a Diretiva das Águas Subterrâneas (DAS) que reconhecem as águas subterrâneas como um recurso natural valioso que, enquanto tal, deverá ser protegido da deterioração e da poluição química. Tal proteção é particularmente importante aos ecossistemas dependentes das águas subterrâneas e à utilização destas águas para o abastecimento destinado ao consumo humano. Salienta-se o intensivo uso da água subterrânea na agricultura no continente Europeu.

A valorização das águas subterrâneas ocorre em nível global, já que são essenciais para a manutenção da vida na Terra. As águas subterrâneas são reservas importantes por estarem disponíveis a qualquer momento, além de apresentarem baixo custo de armazenamento, constituindo-se em alternativa às águas superficiais, sujeitas a alterações mais frequentes na sua qualidade natural. As águas subterrâneas também são fonte de abastecimento em períodos de estiagens para rios e outros mananciais superficiais como nascentes, lagos e banhados. A água subterrânea é uma parte essencial do ciclo hidrológico, que tem importante papel na manutenção da biodiversidade (Custodio e Silva Junior, 2008).

Segundo Eckhardt et al. (2009), as águas subterrâneas vêm assumindo uma importância cada vez mais relevante como fonte de abastecimento, devido a uma série de fatores que restringem a utilização das águas superficiais. Muitos municípios brasileiros possuem seu abastecimento unicamente por meio de águas subterrâneas, pela facilidade de acesso ou mesmo por sua melhor qualidade física e química.

As águas subterrâneas são, contudo, também susceptíveis à contaminação. Segundo Foster et al. (2006), no mundo inteiro, os aquíferos estão sob perigo cada vez maior de contaminação em decorrência da urbanização, do desenvolvimento industrial, das atividades agrícolas e de mineração. Os custos para realizar a descontaminação de aquíferos são elevados tornando o processo inviável, assim é muito mais sensato preservar este recurso natural e renovável.

Dentre as fontes potenciais de poluição de aquíferos estão, também, os cemitérios, os quais liberam um liquido escuro de composição química potencialmente contaminante denominado necrochorume. Esse pode migrar no subsolo em diferentes escalas e com distintas composições físico-químicas e bacteriológicas. Também, os postos de combustíveis, 
que no país operam com óleo Diesel, gasolina e álcool, podendo liberar os BTEX (Benzeno, Tolueno, Etileno e Xileno), além dos hidrocarbonetos totais do petróleo. As lavagens e os lava-a-jato de veículos automotores são potencialmente contaminantes do meio ambiente subterrâneo, necessitando de monitoramento constante em poços construídos para esse fim, buscando identificar e evitar vazamentos de distintos produtos químicos como os resíduos de óleos e graxas (Kemerich et al., 2011).

O município de Nova Palma conta com uma população de 6.342 habitantes, com ocupação média de 20,23 hab. / $\mathrm{km}^{2}$ na área total do Município (IBGE, 2010). De acordo com OEA e GEF (2009), a distribuição da população na área de ocorrência do SAG não é homogênea, variando de 2,5 hab. $/ \mathrm{km}^{2}$ no estado do Mato Grosso a 118,6 hab. $/ \mathrm{km}^{2}$ no estado de São Paulo.

O meio urbano e rural do Município de Nova Palma é abastecido por águas subterrâneas, sendo que a captação, o tratamento com cloro e flúor, a distribuição e a administração na área urbana do município são de responsabilidade da Companhia Rio-Grandense de Saneamento (CORSAN). Uma vez que toda a população urbana do município depende desta fonte subterrânea para as suas múltiplas atividades diárias, esse recurso merece atenção especial e deve ser levado em conta no gerenciamento e gestão, no que diz respeito ao planejamento de uso e ocupação do solo, justificando-se assim a realização deste trabalho.

Ribeiro (2005) discorre sobre índices de vulnerabilidade: “A grande maioria dos métodos de avaliação da vulnerabilidade possuem uma natureza empírica, o que é veículo para o surgimento de um vasto leque de diferentes interpretações por diferentes técnicos. Essa subjetividade vai repercutir forçosamente na atribuição de valores numéricos a entidades de natureza descritiva". Na opinião desse autor torna-se necessário distinguirem-se dois tipos de vulnerabilidade: a intrínseca e a específica. A intrínseca considera unicamente as características geológicas, hidrológicas e hidrogeológicas do meio, sendo por isso independente do tipo de poluente gerado pelas atividades antropogênicas.

Já a vulnerabilidade específica deve ser utilizada sempre que se consideram também as propriedades de um poluente específico e as suas relações com os componentes de vulnerabilidade intrínseca. Neste trabalho, foi considerada a vulnerabilidade como sendo intrínseca.

Foster et al. (2013) consideram que a vulnerabilidade do aquífero se destina a representar a variação do nível de proteção natural ou a capacidade de atenuação do contaminante na zona de solo insaturado ou zona de semi-confinamento da água, localizadas acima do aquífero. Essa contaminação advém de processos físicos e químicos (filtração, biodegradação, hidrólise, adsorção, neutralização, e volatilização dispersão)

O Sistema GOD já foi utilizado na avaliação da vulnerabilidade de aquíferos à contaminação, em rochas sedimentares arenosas formadoras de aquíferos porosos intergranulares, na zona de afloramento (ZA), do Sistema Aquífero Guarani (SAG): OEA e GEF (2009); Silvério da Silva et al. (2007) em Santana do Livramento/Rivera; Martinez et al. (2008) no Município de Santa Cruz do Sul; Marion et al. (2010) no Campus da UFSM; Silvério da Silva e Descovi Filho (2010) na bacia do rio Santa Maria; Kemerich et al. (2011) no Município de Santa Maria; Ertel et al. (2012) no Município de Rosário do Sul; Terra et al. (2013) no Município de Santiago - todos no Estado do Rio Grande do Sul, Brasil.

Adotando a escala de município Löbler et al. (2014) realizaram um estudo de caso no Município de Nova Palma comparando duas bases de dados: uma do Sistema de Informações de Águas Subterrâneas/SIAGAS/CPRM e Imagens STRM (Shuttle Radar Topography Mission) considerando que as duas bases de dados podem ser utilizadas com eficácia no mapeamento de águas subterrâneas em escala local.

De acordo com OEA e GEF (2009), o SAG é a unidade hidroestratigráfica mais importante da porção meridional do continente sul-americano e está associado ao conjunto de 
rochas formadas por sedimentos originados da acumulação mecânica de partículas detríticas (partículas produzidas pela decomposição de rochas preexistentes e denominadas de "siliciclastos" - cascalho, areia, silte e argila) da Bacia do Paraná (Brasil e Paraguai), Bacia Chacoparanaense (Argentina) e Bacia Norte (Uruguai). Ele ocorre em parte de quatro países: na Argentina $\left(228.225 \mathrm{~km}^{2}\right)$, no Brasil $\left(735.918 \mathrm{~km}^{2}\right)$, no Paraguai $\left(87.536 \mathrm{~km}^{2}\right)$ e no Uruguai $\left(36.170 \mathrm{~km}^{2}\right)$.

Já as rochas vulcânicas que cobrem mais da metade do Estado do Rio Grande do Sul constituem aquíferos cristalinos fraturados, pertencentes ao Sistema Aquífero Serra Geral (SASG II) (Machado e Freitas, 2005; Scheibe e Hirata, 2008). Nesse sistema aquífero há aplicações do Sistema GOD no município de Erexim Silvério da Silva et al. (2013); Terra et al. (2013) em Santiago; Löbler et al. (2013), no município de Restinga Seca; e Silvério da Silva et al. (2014), no Município de Boa Vista do Cadeado - todos, também, no estado do Rio Grande do Sul, Brasil.

De acordo com Machado e Freitas (2005), o SASG II ocupa a parte oeste do estado do Rio Grande do Sul, e ocorre na Argentina (Curuzú Cuatiá) e no Uruguai com a denominação de Formação Arapey (OEA e GEF, 2009). Suas litologias são predominantemente constituídas por riólitos, riodacitos e em menor proporção basaltos fraturados. A capacidade específica é inferior a $0,5 \mathrm{~m}^{3} / \mathrm{h} / \mathrm{m}$, entretanto, excepcionalmente em áreas mais fraturadas ou com arenitos na base do sistema, podem ser encontrados valores superiores a $2 \mathrm{~m}^{3} / \mathrm{h} / \mathrm{m}$.

O presente trabalho teve como objetivo elaborar um estudo sobre a vulnerabilidade à contaminação das águas subterrâneas do Município de Nova Palma, com uso do sistema GOD de Foster et al. (2006), aliado ao uso de geotecnologias. Também se realizou o mapeamento dos pontos contaminantes (cemitérios e postos de combustíveis) dentro do município.

O sistema GOD tem fácil aplicabilidade, por ter plena sintonia com os dados disponíveis e ainda, em uma revisão da literatura, se constatou ser um método de bons e confiáveis resultados. Segundo Foster et al. (2006), esse método é adaptado às condições brasileiras e caribenhas, sendo necessário no mínimo o conhecimento de três parâmetros do aquífero. Na literatura existem vários outros métodos de avaliação da vulnerabilidade de aquíferos à contaminação, como o DRASTIC de Aller et al. (1987), que utiliza sete parâmetros, e o Índice de Susceptibilidade (IS) de Ribeiro (2005), que inclui o uso do solo.

\section{MATERIAIS E MÉTODOS}

\subsection{Coleta de dados}

Para a elaboração do presente trabalho utilizaram-se dados secundários, construindo-se um banco de dados referente às captações por poços no município de Nova Palma. Foram reunidos dados através de pesquisas no sítio da Companhia de Pesquisas de Recursos Minerais/CPRM e no Sistema de Informações de Águas Subterrâneas/SIAGAS. Inicialmente se identificou o número de cadastro do poço (ID de 10 dígitos, com o número do poço), as coordenadas no sistema Universal Transversa de Mercator (UTM), a cota altimétrica do terreno (m), a(s) formação(ões) geológica(s) penetrada(s) na perfuração do poço, a condição do meio aquífero (se é livre, confinado ou semi-confinado), o nível estático da água (m) (condição sem bombeamento, ou se é surgente) e os usos da água subterrânea.

Estão cadastrados 36 poços para o município de Nova Palma na base de dados CPRM/SIAGAS, sendo que desses apenas 13 possuíam todos os parâmetros catalogados necessários para aplicar-se o sistema GOD (Foster et al., 2006). Esses parâmetros são: $\mathbf{G}=$ Grau de confinamento do poço, $\mathbf{O}=$ ocorrência de estratos de cobertura litológica penetrados (ex. rochas vulcânicas e sedimentares do Sistema Aquífero Serra Geral/SASG e Sistema Aquífero Guarani/SAG) e $\mathbf{D}=$ nível estático ou nível da água, conforme é apresentado na Figura 1. 
Também foram coletados dados em campo com visitas aos proprietários dos poços, os quais foram sistematizados, e então usados nas avaliações espaciais através de geotecnologias. Estes dados são referentes ao nível estático, para atualizar e mesmo completar as informações disponíveis. Também foram registradas imagens das condições atuais das captações, dos pontos potenciais de contaminação e dos principais usos da água.

Os pontos potencialmente contaminantes foram localizados no território do município, com uso do Global Position System/GPS Garmim Etrex manual. Adotou-se o sistema de coordenadas UTM, com o fuso 22, o Datum horizontal SAD69, e o Datum vertical Porto de Imbituba/Santa Catarina. Esse sistema também é usado pelo SIAGAS da CPRM. No presente estudo foram mapeados dois postos de combustíveis e sete cemitérios no meio urbano e rural do município.

\subsection{Descrição do método}

Foster et al. (2006) caracterizam a vulnerabilidade intrínseca (natural) do aquífero à contaminação, adotando os seguintes parâmetros: (G) Tipo de ocorrência da água subterrânea; (O) Classificação dos estratos acima da zona saturada do aquífero, em termos do grau de consolidação e caráter litológico; (D) Determinação da profundidade do nível freático. A figura 1 descreve passo a passo os procedimentos utilizados, explanando as etapas que compõem o sistema GOD.

Após a pontuação de cada etapa é feito o produto dos três valores, obtendo-se a(s) classe(s) de vulnerabilidade à(s) qual/quais pertence(m) o aquífero. Esta vulnerabilidade pode ser classificada como: desprezível $(0$ a 0,1$)$, baixa $(0,1$ a 0,3$)$, média $(0,3$ a 0,5$)$, alta $(0,5$ a $0,7)$ e extrema $(0,7$ a 1,0$)$.

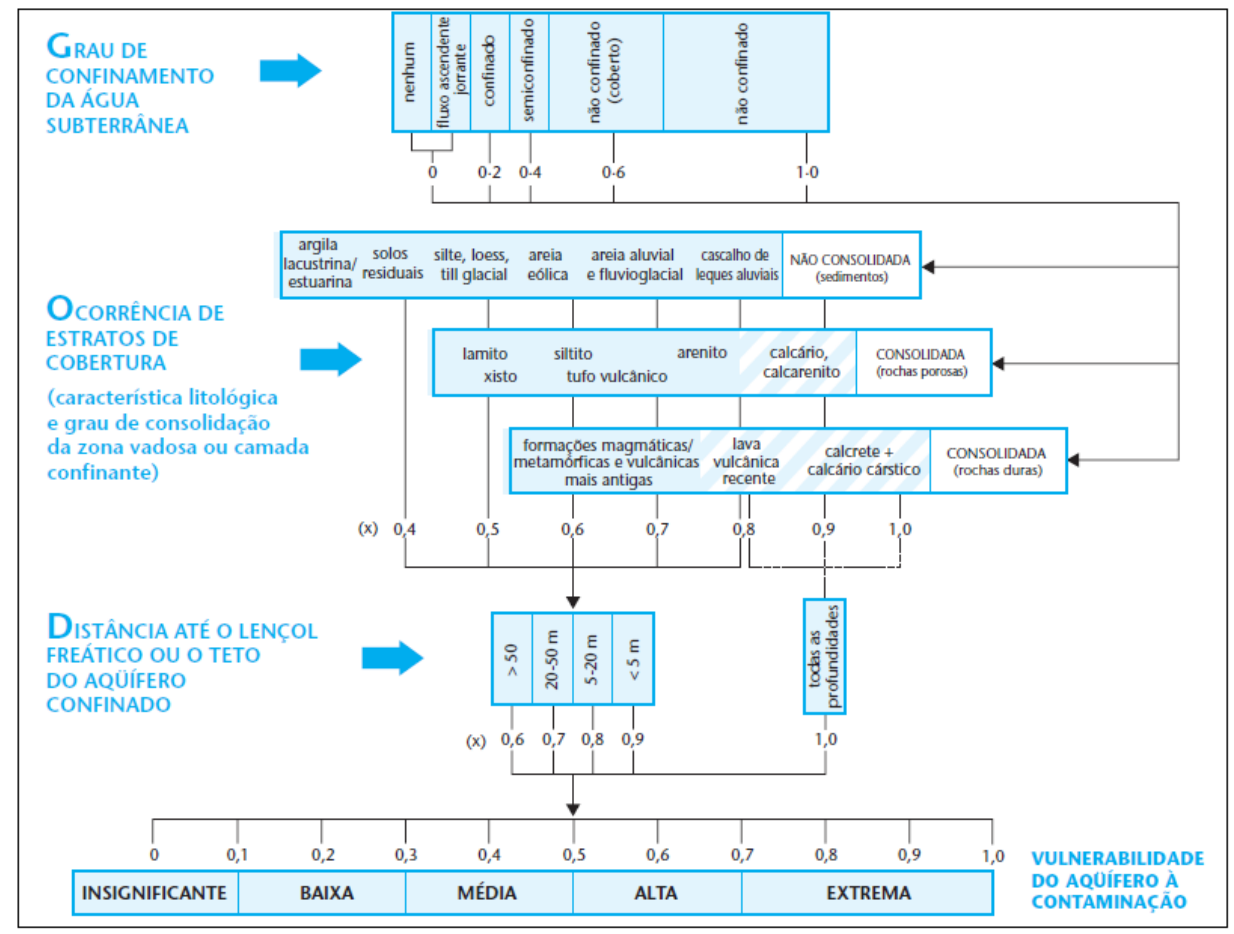

Figura 1. Sistema $G O D$ de avaliação da vulnerabilidade do aquífero à contaminação.

Fonte: Foster et al. (2006).

\subsection{Espacialização dos dados}

A aplicação de geotecnologias permite a espacialização dos pontos de captação de água e ainda a localização do ponto contaminante no mapa das classes de vulnerabilidade à 
contaminação intrínseca, tornando-se possível assim sugerir áreas mais adequadas para instalação de empreendimentos potencialmente poluidores do meio subterrâneo. Esses estudos devem ser acompanhados do uso dos Sistemas de Informações Geográficas/SIGs, que segundo Muradas et al. (2010) permitem a manipulação e atualização dos dados de forma dinâmica e constante.

Para a delimitação da área do estudo, optou-se pelos limites políticos do município de Nova Palma, disponíveis na malha digital do IBGE (2005), com limites municipais e urbanos, e plotados com uso do Programa ArcGIS 10. Após a obtenção dos dados no sistema SIAGAS/CPRM (CPRM, 2013) e em pesquisa de campo, foi realizado o seu tratamento em ambiente SIG.

Para a interpolação dos dados foi usado o programa Surfer 8 e o método de krigagem. Esse foi o que melhor representou a realidade espacial dos pontos distribuídos em vários locais da área avaliada. O Surfer 8 é uma importante ferramenta que utiliza algoritmos matemáticos para gerar suas curvas, otimizando o trabalho do usuário e permitindo sobrepor mapas com diferentes planos de informações. Após isso, foi feito o Overlay (ferramenta desse programa que permite cruzar mapas dentro de uma mesma projeção cartográfica).

Para a construção do mapa de tendência de direção de fluxo das águas subterrâneas, foram usadas as cotas altimétricas extraídas da base de dados CPRM/SIAGAS. Utilizou-se o programa Surfer8 espacializando-se a Superfície Potenciométrica (avaliada pela diferença entre a cota da "boca" do poço e o nível da água em cada poço tubular), indicando a tendência de fluxo das águas subterrâneas. A tendência de direção de fluxo subterrâneo é fundamental para entendermos a dinâmica subterrânea e avaliar possíveis empreendimentos poluidores.

\section{RESULTADOS E DISCUSSÃO}

No município de Nova Palma os principais usos da água subterrânea são para o abastecimento humano (doméstico, urbano e em comunidades rurais) e usos na indústria (múltiplos). Já as águas superficiais possuem uso também na irrigação, principalmente na produção de arroz, e na produção de energia elétrica, com destaque para a Usina Hidroelétrica de Dona Francisca, e ainda para o lazer (recreação, pesca e esportes náuticos).

Conforme se observa na Figura 2, os poços da CORSAN seguem padrões de construção e proteção da ABNT/NBR 12.244/2006 (ABNT, 2006). Estes poços também se encontram de acordo com as normas da legislação estadual que trata da outorga, contidas no Decreto Estadual No 42.047/2002 (Rio Grande do Sul, 2002), e segundo as quais, o poço deve dispor de tubo lateral (tubo guia) para medições de nível da água, hidrômetro, selo sanitário em concreto com no mínimo $1 \mathrm{~m}^{2}$ de área e uma área cercada com cerca de $10 \mathrm{~m}$, que visa impedir o acesso de pessoas não autorizadas e de animais.
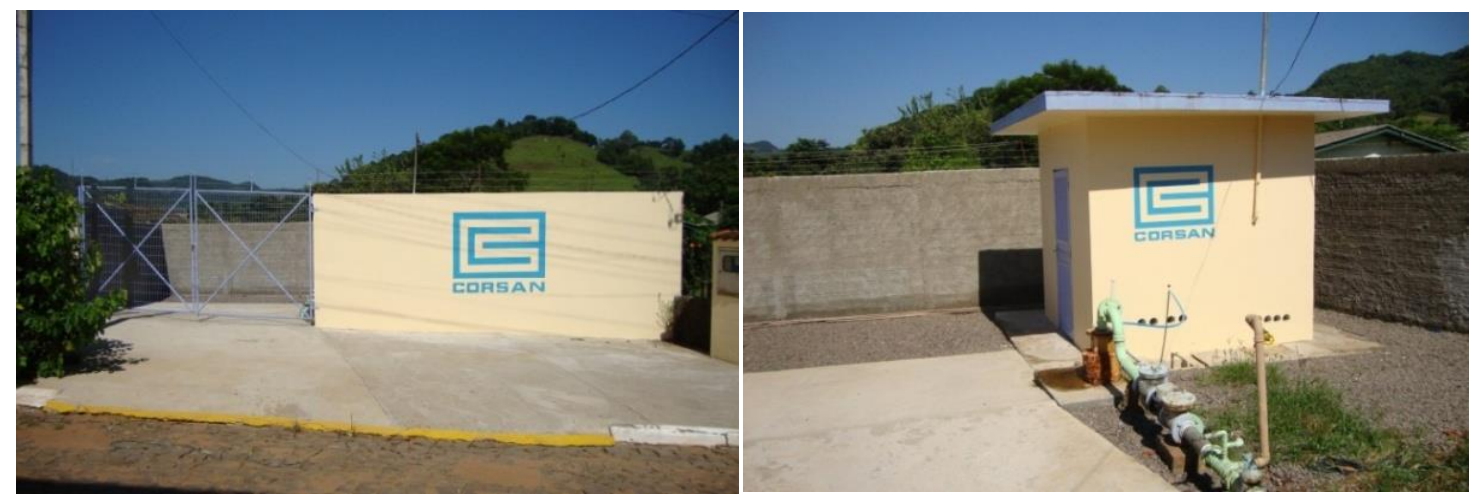

Figura 2. Imagens do poço 4300007677/SIAGAS/CPRM, localizado na área urbana do município de Nova Palma, RS. 
Após serem elaborados os parâmetros e intervalos de valores no sistema GOD para as captações de água subterrânea, conforme apresentado na Figura 1 e Tabela 1, constatou-se que o município de Nova Palma apresenta em seu território cinco níveis de vulnerabilidade: $7,69 \%$ dos poços estão em área da classe de vulnerabilidade insignificante e de 15,38\% na de vulnerabilidade baixa. Já 30,76\% estão em área de vulnerabilidade média, 30,76\% em área de vulnerabilidade alta. E finalizando, na área da classe de vulnerabilidade extrema situam-se 15 , $38 \%$ das captações do município.

$\mathrm{Na}$ Tabela 1 são apresentados alguns aspectos relativos às captações, selecionados para aplicação do sistema GOD. Observa-se que o nível estático dos poços varia entre um mínimo de 0,90 m, quase surgente (aflorante), até cerca de 80,00 m. Também é apresentado o principal uso da água, que ocorre na categoria de abastecimento público (doméstico e/ou urbano) coincidindo com outras áreas do SAG no Brasil, de acordo com OEA e GEF (2009).

Tabela 1. Captações em 13 poços tubulares selecionados para aplicação do Sistema GOD.

\begin{tabular}{cclccc}
\hline $\begin{array}{c}\mathbf{N}^{\circ} \text { Cadastro } \\
\text { CPRM }\end{array}$ & $\begin{array}{c}\text { Nível Estático } \\
\text { (metros) }\end{array}$ & $\begin{array}{c}\text { Uso Água } \\
\text { (Abastecimento) }\end{array}$ & $\begin{array}{c}\text { Nota } \\
\boldsymbol{G O D}\end{array}$ & $\begin{array}{c}\text { Classe de } \\
\text { Vulnerabilidade }\end{array}$ & $(\boldsymbol{\%})$ \\
\hline 4300007696 & 80,00 & Doméstico & 0,07 & Insignificante & 7,69 \\
4300002707 & 5,50 & Urbano & 0,29 & Baixa & - \\
4300007703 & 20,00 & Doméstico & 0,29 & Baixa & 15,38 \\
4300002705 & 2,29 & Urbano & 0,32 & Média & - \\
4300007678 & 1,39 & Múltiplo & 0,38 & Média & - \\
4300007715 & 20,00 & Doméstico & 0,34 & Média & 30,76 \\
4300002706 & 1,39 & Urbano & 0,38 & Média & - \\
4300002703 & 1,33 & Urbano & 0,54 & Alta & - \\
4300007675 & 1,33 & Múltiplo & 0,63 & Alta & - \\
4300007679 & 5,50 & Urbano & 0,64 & Alta & 30,76 \\
4300007677 & 1,89 & Urbano & 0,63 & Alta & - \\
4300007676 & 0,90 & Múltiplo & 0,81 & Extrema & - \\
4300002704 & 0,90 & Urbano & 0,72 & Extrema & 15,38 \\
\hline
\end{tabular}

Fonte: Organizado a partir da CPRM (2013).

As principais fontes pontuais potencialmente poluidoras encontradas no município foram: sete cemitérios de diferentes dimensões e dois postos de combustíveis, como se pode observar no mapa temático da Figura 3.

Com base nos dados coletados foi possível elaborar um mapa de pontos potenciais de contaminação localizados dentro do Município de Nova Palma. Na Figura 3 observa-se que a maioria dos poços está localizada em áreas de alta e média vulnerabilidade. Levando-se em conta que a maioria das fontes potenciais de poluição, tais como postos de combustíveis, cemitérios, despejos de esgotos estão concentradas na área urbana, deve-se manter um acompanhamento e monitoramento frequente para proteger as captações de águas subterrâneas, uma vez que essas são muito importantes no abastecimento doméstico e urbano do Município de Nova Palma, representando mais de 76\% dos usos (Tabela 1).

Observa-se ainda no mapa da Figura 3 que existem duas áreas de alta vulnerabilidade a oeste e a leste, com uma faixa extensa que vai de sul a norte apresentando uma vulnerabilidade baixa e insignificante. As áreas de maior vulnerabilidade geralmente se encontram próximas aos maiores rios que drenam a Bacia Hidrográfica onde se insere o município (Bacia G50/Alto Jacuí, classificação da Secretaria Estadual de Meio 
Ambiente/SEMA - RS), o rio Soturno e o rio Jacuí (figuras 3 e 4). Geralmente as planícies aluviais destes cursos de água apresentam nível freático próximo da superfície do terreno, caracterizando-as como mais vulneráveis à contaminação difusa. Vale ressaltar que essas áreas ribeirinhas são usadas para o cultivo do arroz irrigado, onde se utilizam fertilizantes a base de Nitrogênio, Fósforo e Potássio (NPK), além de agrotóxicos.
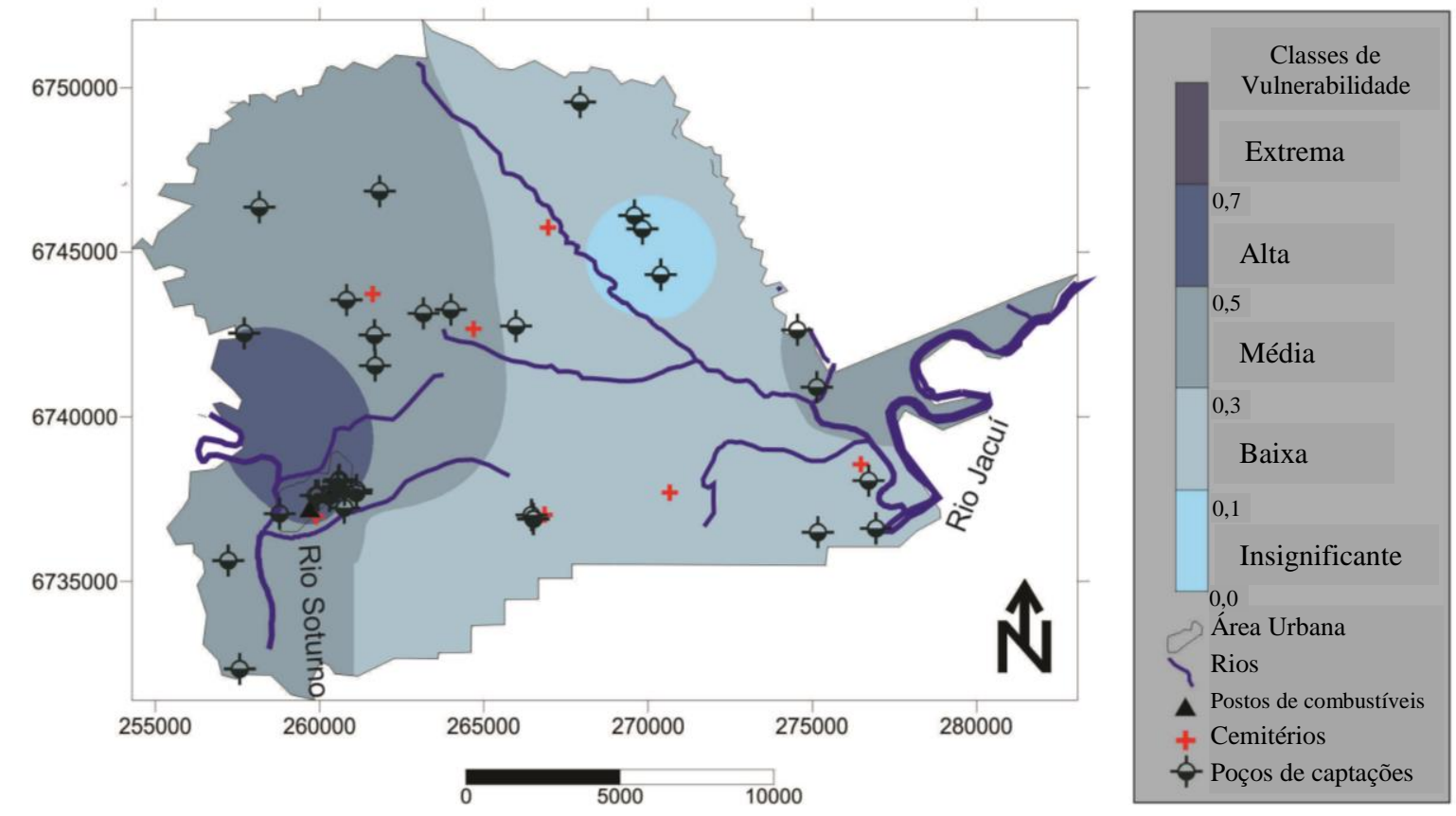

Figura 3.Mapa dos pontos potenciais de contaminação, poços tubulares de abastecimento, drenagem e vulnerabilidade GOD para o município de Nova Palma, RS.

Fonte: Malha digital de limite municipal e urbana do IBGE, dados CPRM/SIAGAS (sistema de coordenadas UTM, fuso 22) e trabalhos de campo.

Analisando-se o mapa de tendência de direção de fluxo subterrâneo (com base na superfície potenciométrica) apresentado na Figura 4, observa-se que os vetores indicam o fluxo da água subterrânea em direção aos principais cursos de água (Rio Jacuí e Rio Soturno), evidenciando uma contribuição do aquífero na perenização do fluxo de base dos rios, mesmo em períodos de estiagem. Esse comportamento está descrito em OEA e GEF (2009). Segundo Feitosa e Manoel Filho (2008), "em zonas de fluxo local de águas subterrâneas, parte da recarga alimenta o fluxo de base da rede de drenagem existente. Este tipo de contribuição denomina-se curso efluente, onde o aquífero cede água para o rio".

Como a água subterrânea assume principalmente dois sentidos, um sul e sudeste em direção à calha do Rio Jacuí e outro, oeste, em direção à calha do Rio Soturno, estima-se que as captações de água subterrânea localizadas próximas às calhas desses rios apresentem menor probabilidade de ficar sem água em períodos menos chuvosos (estiagens), devido à resposta aquífera ser suficiente para sua manutenção.

Também se deve levar em conta que há tendência de a direção de fluxo ser indicativa do movimento subterrâneo de água de um ponto com extrema ou alta vulnerabilidade para outros locais, podendo aumentar os riscos de contaminação, pois também se deve considerar o movimento lateral, que também é fonte de recarga de aquíferos (Custódio e Silva Jr., 2008). 


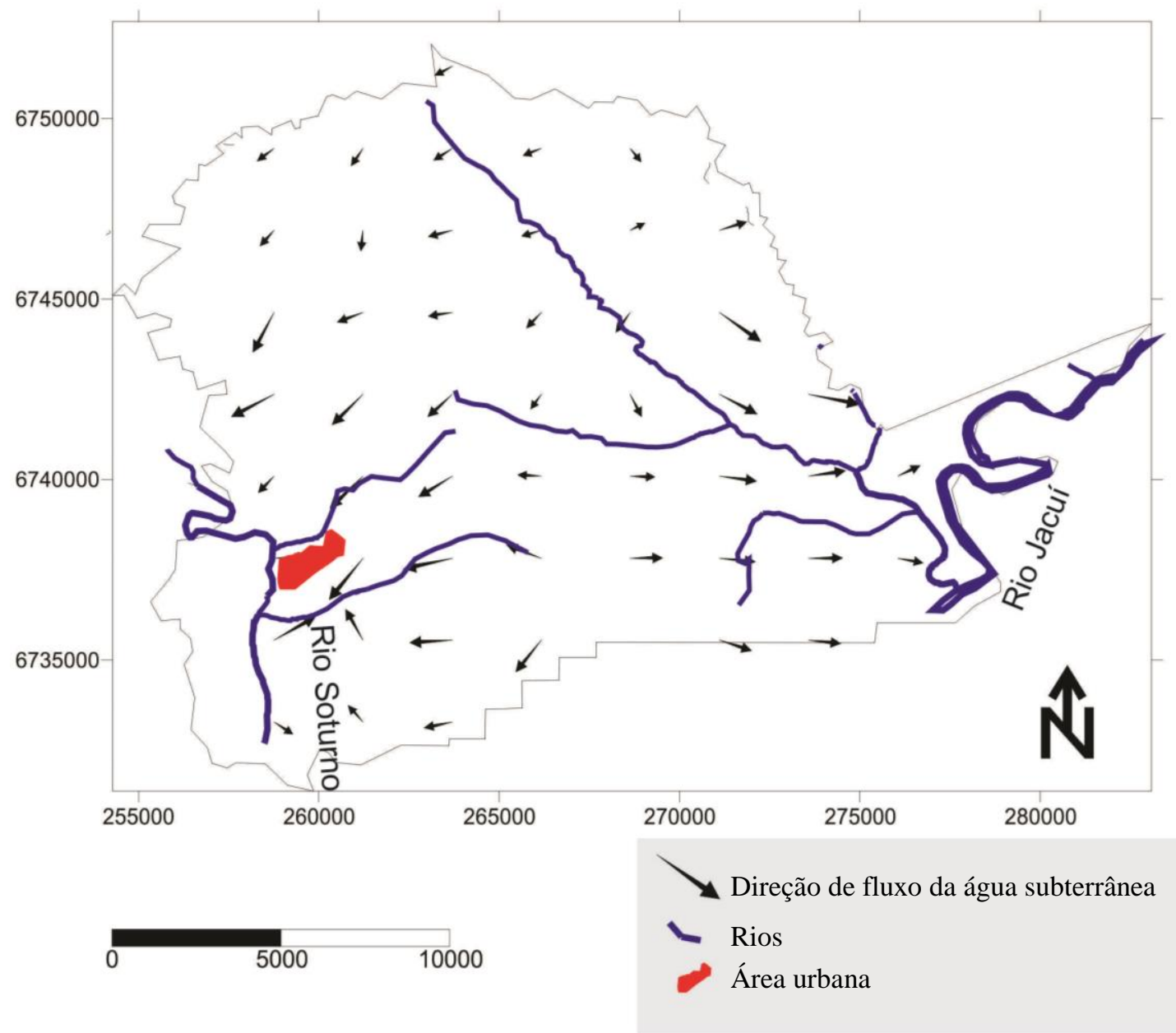

Figura 4. Mapa das tendências de direção dos fluxos das águas subterrâneas no Município de Nova Palma. Inclui seus principais rios, da Bacia Hidrográfica do Alto Jacuí (G50).

Fonte: Malha digital de limite municipal e urbana do IBGE e dados CPRM/SIAGAS (sistema de coordenadas UTM, fuso 22).

\section{CONCLUSÕES}

Os derrames de rochas vulcânicas exercem papel importantíssimo para o SAG na região: servem como proteção natural dos arenitos que estão confinados e que produzem água subterrânea com altas vazões.

As classes de vulnerabilidade predominantes foram a média e a alta, sugerindo-se atenção especial dos órgãos gestores em relação ao uso e à ocupação dos solos, na implantação de empreendimentos que possam causar algum tipo de contaminante no meio subterrâneo, e monitoramento dos já existentes. Portanto, sugere-se precaução no licenciamento ambiental do município.

A pesquisa contribuiu para a ampliação dos conhecimentos relativos às captações de água subterrânea no Município de Nova Palma, subsidiando assim a sua preservação ambiental e seu gerenciamento tanto na Zona de Afloramentos do Sistema Aquífero Guarani quanto na sua Zona de Confinamento, pelo Sistema Aquífero Serra Geral (OEA e GEF, 2009). Portanto, o sistema GOD apresentou resultados aproveitáveis para a área. 


\section{AGRADECIMENTOS}

Ao CNPq pela bolsa de iniciação cientifica no período da graduação e a FAPERGS/CAPES pela bolsa de mestrado conforme Edital 14/2012 concedidas ao autor principal. À CAPES pela bolsa de estágio sênior, Processo BEX 3954/13-7 concedida ao co-autor.

\section{REFERÊNCIAS}

ALLER, L. et al. DRASTIC: a standardized system for evaluating groundwater pollution potential using hydrogeologic setting. Washington: USEPA, 1987. 58 p.

ASSOCIAÇÃO BRASILEIRA DE NORMAS TÉCNICAS - ABNT. NBR 12244:2006. Poço tubular - construção de poço tubular para captação de água subterrânea. Rio de Janeiro, 2006.

COMPANHIA DE PESQUISA EM RECURSOS MINERAIS. Sistema de Informações de Águas Subterrâneas. Cadastro de poços tubulares do município de Nova Palma. Disponível em: <http://siagasweb.cprm.gov.br/layout/>. Acesso em: 20 jun. 2013.

CUSTODIO, E.; SILVA JUNIOR, G. C. da. Conceptos básicos sobre o papel ambiental das águas subterrâneas e os efeitos da sua explotação. Boletín Geológico y Minero, v. 119, p. 93-106, 2008.

ECKHARDT, R. R.; DIEDRICH, V. L.; FERREIRA, E. R.; STROHSCHOEN, E.; DEMAMAN, L. C. Mapeamento e avaliação da potabilidade da água subterrânea do Município de Lajeado, RS, Brasil. Revista Ambiente \& Água, Taubaté, v. 4, n. 1, p. 58-80, 2009. http://dx.doi.org/10.4136/ambi.agua.74

ERTEL, T.; LÖBLER, C. A.; SILVÉRIO DA SILVA, J. L. Índice de Vulnerabilidade das Águas Subterrâneas no Município de Rosário do Sul, Rio Grande do Sul. Revista Eletrônica em Gestão, Educação e Tecnologia Ambiental, Santa Maria, v. 7, p. 1400 -1408, 2012. http://dx.doi.org/10.5902/223611705962

FEITOSA, F. A. C.; MANOEL FILHO, J. Hidrogeologia: conceitos e aplicações. 3. ed., rev. e ampl. Rio de Janeiro: CPRM; LABHIH, 2008. 812 p.

FOSTER, S.; HIRATA, R.; GOMES, D.; D’ELIA, M.; PARIS, M. Proteção da qualidade da água subterrânea: um guia para empresas de abastecimento de água, órgãos municipais e agências ambientais. São Paulo: Servemar, 2006.

FOSTER, S.; HIRATA, R.; ANDREO, B. The aquifer pollution vulnerability concept: aid or impediment in promoting groundwater protection? Hydrogeology Journal, p. 737-750, 2013. http://dx.doi.org/10.1007/s10040-013-1019-7

INSTITUTO BRASILEIRO DE GEOGRAFIA E ESTATÍSTICA - IBGE. Censo demográfico 2010. Disponível em: http://www.censo2010.ibge.gov.br>. Acesso em: 21 jul. 2013.

INSTITUTO BRASILEIRO DE GEOGRAFIA E ESTATÍSTICA - IBGE. Malha municipal digital do Brasil: situação em 2005. Rio de Janeiro, 2007. 1 CD-ROM 
KEMERICH, P. D. C.; SILVÉRIO DA SILVA, J. L.; DESCOVI FILHO, L. L. V.; VOLPATTO, F.; SAUCEDO, E. M. Determinação da vulnerabilidade natural à contaminação da água subterrânea no Bairro Nossa Senhora do Perpétuo Socorro em Santa Maria-RS. Engenharia Ambiental, v. 1, p. 85-98, 2011.

LÖBlER, C. A.; SILVÉRIO DA SILVA, J. L.; MARTELli, G. V.; ERTEL, T. Pontos Potenciais de Contaminação e Vulnerabilidade Natural das Águas Subterrâneas do Município de Restinga Seca - RS. Revista Brasileira de Geografia Física, v. 6, n. 3, p. 500-509, 2013.

LÖBLER, C. A.; TERRA, L. G.; SILVÉRIO DA SILVA, J. L. Dados da CPRM/SIAGAS e Imagens STRM como Base Cartográfica na Elaboração de Mapeamento em Recursos Hídricos Subterrâneos em Escala Municipal: o Caso de Nova Palma, RS. Revista Brasileira de Geografia Física, v. 7, n. 3, p. 513-523, 2014.

MACHADO, J. L. F.; FREITAS, M. A. Projeto mapa hidrogeológico do estado do Rio Grande do Sul: escala 1:750.000: relatório final. Porto Alegre: CPRM, 2005.

MARION, F. A.; MELlO FILHO, J. A. S.; SILVÉRIO DA SILVA, J. L. Análise da vulnerabilidade natural das águas subterrâneas por geoprocessamento no Campus da UFSM/RS. Terr@ Plural, v. 4, p. 65-76, 2010.

http://dx.doi.org/10.5212/TerraPlural.v.4i1.065076

MARTINEZ, M. M.; SILVÉRIO DA SILVA, J. L.; LOPES, G. N. Avaliação da vulnerabilidade das águas subterrâneas no município de Santa Cruz do Sul, RS/Brasil. Agro@mbiente On-line, v. 2, p. 1-8, 2008.

MURADÁS, K.; COELHO, O. G. W.; WOJAHN, D. Levantamento de dados geomorfológicos e hidrogeológicos para mapeamento de vulnerabilidade de contaminação do Aquífero Guarani nos municípios de Portão e Estância Velha/RS utilizando o método DRASTIC. Revista Ambiente \& Água, Taubaté, v. 5, n. 3, p. $172-$ 194, 2010. http://dx.doi.org/10.4136/ambi-agua.161

ORGANIZAÇÃO DOS ESTADOS AMERICANOS - OEA; GLOBAL ENVIRONMENT FACILITY - GEF. Projeto de proteção ambiental e desenvolvimento sustentável do Sistema Aquífero Guarani. Programa Estratégico de Ação - PEA. [S.1.], 2009. 102 p. (Manuais e Documentos Técnicos, 5)

RIBEIRO, L. F. T. Um novo índice vulnerabilidade específico de aquíferos: formulação e aplicações. In: SIMPÓSIO DE HIDRÁULICA E RECURSOS HÍDRICOS DOS PAÍSES DE LÍNGUA OFICIAL PORTUGUESA (SILUSBA), 7., 2005, Évora. Anais... Évora: [s.n.], 2005. p. 16.

RIO GRANDE DO SUL. Secretaria do Meio Ambiente. Decreto n. 42.047, de 26 de dezembro de 2002. Disponível em: http://www.legislacao.sefaz.rs.gov.br/Site/ Document.aspx ?inpKey=106552\&inpCodDispositive=\&inpDsKeywords=10350.

Acesso em: out. 2014.

SCHEIBE, L. F.; HIRATA, R. O contexto tectônico dos sistemas aquíferos Guarani e Serra Geral em Santa Catarina: uma revisão. In: CONGRESSO BRASILEIRO DE ÁGUAS SUBTERRÂANEAS, 15., 2008, Natal. Anais... Natal: ABAS, 2008. 1 CD-ROM. 
SILVÉRIO DA SILVA, J. L.; BESSOUAT, C.; CAMPONOGARA, I.; FRANTZ, L. C.; GUIMARAENS, M.; FLORES, E. M. et al. Caracterização de áreas de recarga e descarga do SAG em Santana-Rivera e Quarai-Artigas. Estudo da vulnerabilidade na área de influência de Quarai-Artigas. In: ROBERTO MONTES, R. Aqüífero Guarani: avanços no conhecimento para sua gestão sustentável. Montevideu: Secretaria General del Proyecto Aquifero Guarani/OEA, 2007. v. 1, p. 1-20.

SILVÉRIO DA SILVA, J. L.; DESCOVI FILHO, L. L. V. Vulnerabilidade das águas subterrâneas na bacia hidrográfica do rio Santa Maria-RS. Revista Águas Subterrâneas, v. 24, p. 1-17, 2010.

SILVÉRIO DA SILVA, J. L.; DESCOVI FILHO, L. L. V.; LORENSI, R. P.; CRUZ, J. C.; ELTZ, F. L. Vulnerabilidade do aquífero serra geral à contaminação no município de Erechim - Rio Grande do Sul - Brasil. Ciência e Natura, v. 35, p. 10-23, 2013. http://dx.doi.org/10.5902/2179-460X0746

SILVÉRIO DA SILVA, J. L.; NASCIMENTO, L. M.; LÖBLER, C. A. Mapeamento das águas subterrâneas do município de Boa Vista do Cadeado/RS. Revista Monografias Ambientais, v. 14, p. 3061-3074, 2014. http://dx.doi.org/10.5902/223613085688

TERRA, L. G.; LÖBLER, C. A.; SILVÉRIO DA SILVA, J. L. Estimativa da vulnerabilidade à contaminação dos recursos hídricos subterrâneos do município de Santiago-RS. Revista Eletrônica em Gestão, Educação e Tecnologia Ambiental, v. 10, p. 22082218, 2013. http://dx.doi.org/10.5902/223611707887

UN-WATER. Policy brief: water quality. 2011. 22 p. Disponível em: <http://www.unwater.org/> Acesso em: 20 dez. 2013. 